wWw.volsu.ru

DOI: https://doi.org/10.15688/jvolsu11.2017.2.3

UDC 504.054:622.276

LBC 20.18

\title{
THE METHOD OF CLEANING SOIL FROM OIL POLLUTION BY USING NATURAL SORBENTS
}

\author{
Baira V. Tsombueva \\ Kalmyk State University named after B.B. Gorodovikov, Elista, Russian Federation \\ Zinaida V. Goryashkieva \\ Kalmyk State University named after B.B. Gorodovikov, Elista, Russian Federation \\ Lyubov F. Shcherbakova \\ Yuri Gagarin State Technical University of Saratov, Saratov, Russian Federation
}

\begin{abstract}
The authors investigate the sorption properties of natural materials - wool and peat, as well as woodworking industry wastes - sawdust, which are used for cleaning oil-contaminated soils of Kalmykia. The degree of oil extraction from light chestnut soils using wool is $59.67 \%$. Applying the multi-component sorbents leads to substantial increase of sorption capacity up to $70.3 \%$. The studies include the assessment of oil influence on the chemical composition of the soil, the analysis of the content before and after pollution. Oil pollution affects the concentration of water-soluble salts, leads to soils alkalinization and restructuring of the soil-absorbing complex. The study has established that natural sorbents are able to change the chemical composition of oil-contaminated soils. The wool can be reused after washing it with chloroform and regeneration. The repeated use of sorbents lead to reduction of oil consumption by wool by $11.6 \%$, sawdust $-30.6 \%$, peat $-6.8 \%$.

Thus, the authors have come to conclusion that the use of natural sorbents is promising in the study and forecasting of areas contaminated with oil and oil products.
\end{abstract}

Key words: oil-contaminated soils, natural sorbents, oil, wool, sawdust, peat, sorption.

УДК 504.054:622.276

ББК 20.18

\section{МЕТОД ОЧИСТКИ ПОЧВЫ ОТ НЕФТЯНОГО ЗАГРЯЗНЕНИЯ С ПОМОЩЬЮ ПРИРОДНЫХ СОРБЕНТОВ}

\section{Баира Викторовна Цомбуева}

Калмыцкий государственный университет имени Б.Б. Городовикова, г. Элиста, Российская Федерация

\section{Зинаида Валериевна Горяшкиева}

Калмыцкий государственный университет имени Б.Б. Городовикова, г. Элиста, Российская Федерация

\section{Любовь Федоровна Щербакова}

Саратовский государственный технический университет имени Ю.А. Гагарина, г. Саратов, Российская Федерация

Аннотация. Изучены сорбционные свойства природных материалов - шерсти и торфа, а также отходов деревообрабатывающей промышленности - опилок, применяемых для очистки нефтезагрязненных почв Калмыкии. Установлено, что шерсть может быть предложена в качестве сорбента при очистке нефтезагрязненных почв. Степень извлечения нефти из почв при использовании шерсти достигает 59,67 \%. Применение многокомпонентных сорбентов приводит к существенному увеличению сорбционной емкости до 70,3 \%. 


\section{ЭКОЛОГИЯ И ПРИРОДОПОЛЬЗОВАНИЕ}

Использование природных сорбентов представляется перспективным при исследовании и прогнозировании территорий, загрязненных нефтью и нефтепродуктами.

Ключевые слова: нефтезагрязненные почвы, природные сорбенты, нефть, шерсть, опилки, торф, сорбция.

Калмыкия является одним из нефтедобывающих регионов в Нижнем Поволжье. В процессе добычи, транспортировки и переработки нефти происходит загрязнение окружающей среды, особенно сильное негативное воздействие испытывает почвенный покров.

Технологические процессы добычи и производства нефтепродуктов, их хранение и транспортировка неизбежно связаны с потерями. Такие как, несовершенство систем сбора и транспорта нефти; неисправность устьев оборудования скважин и перекачивающих насосов; низкая степень герметизации сырьевых и товарных резервуаров и многих других потерь [7].

Токсическое действие углеводородов нефти отрицательно воздействует на почвенный покров, а именно, изменяет морфологию, физические и химические свойства почв [13; 20]. Богатые парафинами, смолами, асфальтенами, компоненты нефти закупоривают поры и каналы почвы, в результате создаются анаэробные условия, что приводит к нарушению влагообмена в почве и окислительновосстановительных процессов [9; 11]. Гидрофобный подпочвенный слой из смеси сырой нефти и почвы понижает влагоемкость, но увеличивает способность к накоплению влаги в верхних слоях [12].

Нефть проникает на глубину 5-10 см, хотя иногда мощность битуминизированного слоя достигает 40-50 см. Глубина и скорость проникновения нефти зависит от физико-географической зоны [4].

В результате нефтяных загрязнений меняется строение почв. Происходит слипание мелких частиц с образованием крупных, или насыщения микрочастиц нефтью, которые становятся водоустойчивыми. Меняется характер границ между горизонтами, заметно увеличивается вязкость и плотность почвенной массы [5]. В почвах происходит подщелачивание, $\mathrm{pH}$ водной взвеси в верхних горизонтах почв увеличивается на 1-2 единицы. Наличие нефти и нефтепродуктов понижает самоочищающую способность почвы. Пре- кращение роста растений наблюдается при концентрации в почве 3500 мг/кг почвы [17].

При чрезвычайно сильном загрязнении основную роль в негативном влиянии играют трудноразложимые тяжелые фракции [13]. Тяжелые фракции нефти образуют механический барьер между корневой системой и окружающей средой, затрудняющий питательный и водно-воздушный режим [18].

Многие составляющие нефти могут легко усваиваться через корневую систему растений и создавать повышенные уровни их содержания в биомассе [19]. Стимулирующий рост растений часто отмечается в условиях полупустынь и пустынь на богатых битумами почвах, находящихся над районами глубинных разломов нефтеносных территорий. Длина таких растений в 2-3 раза выше, чем на незагрязненных участках, нарушаются нормальные пропорции во внешнем облике растений, возникают наплывы, наросты, утолщения, придающие отдельным экземплярам уродливый облик, наблюдается сильная поврежденность растений вредителями [15].

Среди методов, применяемых для восстановления нефтезагрязненных и нарушенных земель, сорбционная очистка является одним из наиболее действенных. В качестве сорбентов применяют в основном пористые материалы: золу, кокс, торф, силикагели, алюмогели, активные глины, пенополимеры и различные промышленные и сельскохозяйственные отходы производства и т. д. [8].

В настоящее время существует большое количество методов, с помощью которых снижают и ликвидируют загрязнения нефтью и нефтепродуктами [8; 14; 16].

Выбор и применение какого-либо метода очистки должен быть сделан только после того, как будут получены результаты о качестве обрабатываемой поверхности почв [1; 2].

\section{Объекты и методы исследования}

В работе были исследованы сорбционные свойства природных сорбентов: шерсти, 
гумусового мелиоранта на основе торфа, а также отходов деревообрабатывающей промышленности - опилок.

Известно, что шерсть, является одним из лучших природных сорбентов: 1 кг шерсти может поглотить до 8-10 кг нефти, при этом природная упругость шерсти позволяет отжать большую часть легких фракций нефти. Однако, после нескольких таких отжимов шерсть превращается в битуминизированный войлок и становится непригодной для использования.

Опилки - это недорогой экологически чистый, удобный в использовании и утилизации природный сорбент. Сорбент из опилок обладает хорошими водоотталкивающими свойствами; высокой поглотительной способностью по отношению к нефти и нефтепродуктам; работает в широком диапазоне температур, включая и отрицательные.

Тор $\not$ - многокомпонентное природное образование, имеющее в своем составе различные минеральные и органические соединения. В него входят азот, фосфор, калий, кальций и микроэлементы. Нами был взят гумусовый мелиорант «Нисаба» экологически безвредный и экономически высокоэффективный продукт, как биологический стимулятор, необходимый для роста и развития сельскохозяйственных культур, особенно на низкоплодородных почвах [6].

В качестве сорбата использовалась нефть Улан-Хольского месторождения, расположенного на юго-востоке республики Калмыкия. В качестве экспериментального материала были выбраны светло-каштановые почвы, занимающие большие площади в Республике Калмыкия. Почвы характеризуются невысоким накоплением гумуса (до 2 \%), незначительной глубиной промачивания почвы влагой и интенсивным вымыванием солевых продуктов почвообразования. Почвообразующими породами служат лёссовидные отложения от легкосуглинистого до тяжелосуглинистого гранулометрического состава [3].

Для определения водопоглощения используемых сорбентов, сорбционный материал массой 3 г сплошным слоем наносился на поверхность воды. После насыщения сорбента водой с помощью сита или колонки сорбент снимался. Водопоглощение определяется от- ношением массы поглощенной водой к массе сорбента, потраченного на сорбцию:

$$
B=\frac{m_{\text {погл }}-m_{\text {сорб }}}{m_{\text {сорб }}},
$$

где $B$ - водопоглощение, г/г; $m_{\text {погл }}$ - масса сорбента с поглощенной водой, $г ; m_{\text {сорб }}-$ масса сорбционного материала, г [8].

Для определения нефтеемкости сорбентов сорбционный материал массой 3 г помещался на ровную поверхность и искусственно загрязнялся нефтью до полного насыщения. После этого сорбент взвешивался, и находилась масса нефти, удерживаемой сорбционным материалом.

Сорбционная емкость рассчитывается отношением массы нефти, которую поглотил сорбент к массе самого сорбента.

Сорбционную емкость рассчитывали по формуле:

$$
A=\frac{m_{\text {(нефти) }}}{m_{\text {(сорбента) }}},
$$

где $A$ - нефтеемкость, г/г; $m_{\text {(нефти) }}$ - масса нефти, сорбированная сорбентом, г; $m_{\text {(сорбента) }}-$ масса сорбента, г [8].

Для того, чтобы выявить долю абсолютного количества $(\mathrm{S}, \%)$ извлекаемой нефти необходимо определить количество нефтепродуктов в почве.

Определение содержания нефтепродуктов проводили флуориметрическим методом. Нефтепродукты экстрагировали из почв органическим растворителем (гексаном). Концентрированный экстракт подвергался очистке методом колоночной хроматографии с дальнейшим количественным измерением интенсивности флуоресценции очищенного экстракта на анализаторе «ФЛЮОРАТ-02» [10].

\section{Результаты исследования и их обсуждение}

В работе были изучены следующие сорбционные свойства природных сорбентов (шерсти, торфа и опилок): сорбционная емкость (нефтеемкость), насыпная плотность, водопоглощение, возможность повторного ис- 


\section{ЭКОЛОГИЯ И ПРИРОДОПОЛЬЗОВАНИЕ}

пользования сорбентов. Результаты основных свойств сорбентов приведены в таблице 1 .

Исследования показали, что наименьшая насыпная плотность наблюдается у шерсти -

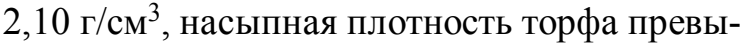
шает значения для шерсти почти в 25 раз.

Поглощая воду, сорбционные материалы увеличиваются в своем весе, впоследствии этого уменьшается их нефтеемкость, а значит, уменьшается эффективность использования сорбционных материалов. Наибольшее значение водопоглощения показала шерсть 5,57 (г/г), наименьшее значение - торф 1,00 (Г/г).

Одним из главных показателей эффективности сорбционного материала является его сорбционная способность (нефтеемкость), зависящая от степени удельной поверхности: чем больше удельная поверхность, тем выше сорбирующая способность. Наибольшей нефтеемкостью обладает нефть 11,3 (г/г), нефтеемкость торфа в 10 раз меньше.

Для оценки возможности повторного использования, изучаемых природных сорбентов для очистки почвы от нефти были определены значения вторичной нефтеемкости сорбентов после промывки и регенерации. Результаты приведены в таблице 2.

По полученным результатам можно сказать, что при повторном использовании сорбентов нефтеемкость шерсти снизилась на $11,6 \%$, опилок на $30,6 \%$, нефтеемкость торфа практически не изменилась. Такие значения нефтеемкости после промывания и регенерации сорбционных материалов указывают на то, что возможно повторное использование шерсти и торфа для сорбции нефти.

Для исследования сорбционных свойств исследуемых сорбентов в почвах, загрязненных нефтью были проведены модельные опыты (табл. 3).

Сорбенты помещали на поверхность почвы массой 500 г, загрязненной нефтью, выдерживали некоторое время, затем удаляли сорбент и определяли количество нефтепродуктов в почве флуориметрическим методом.

Основные свойства сорбционных материалов

Таблица 1

\begin{tabular}{|l|c|c|c|c|}
\hline Сорбент & $\begin{array}{c}\text { Насыпная } \\
\text { плотность, } \mathrm{\Gamma} / \mathrm{cm}^{3}\end{array}$ & $\mathrm{pH}$ & $\begin{array}{c}\text { Водопогло- } \\
\text { щение, } \mathrm{\Gamma} / \Gamma\end{array}$ & $\begin{array}{c}\text { Нефтеемкость, } \\
\text { г/г }\end{array}$ \\
\hline Шерсть & $2,10 \pm 0,2$ & 10,90 & $5,57 \pm 0,2$ & $11,30 \pm 0,2$ \\
\hline Опилки & $7,00 \pm 0,2$ & 7,40 & $3,03 \pm 0,2$ & $5,73 \pm 0,2$ \\
\hline Торф & $49,56 \pm 0,2$ & 6,17 & $1,00 \pm 0,2$ & $1,18 \pm 0,2$ \\
\hline
\end{tabular}

Повторное использование сорбционных материалов

Таблииа 2

\begin{tabular}{|c|c|c|}
\hline Сорбент & Нефтеемкость, г/г & Нефтеемкость повторная, г/Г \\
\hline Шерсть & $11,30 \pm 0,2$ & $9,90 \pm 0,2$ \\
\hline Опилки & $5,70 \pm 0,2$ & $3,90 \pm 0,2$ \\
\hline Торф & $1,18 \pm 0,2$ & $1,10 \pm 0,2$ \\
\hline
\end{tabular}

Таблица 3

Степень извлечения нефти при очистке природными сорбентами

\begin{tabular}{|l|c|c|c|c|c|}
\hline \multirow{2}{*}{ Сорбент } & \multicolumn{4}{|c|}{ Степень извлечения нефти (S), \% через: } \\
\cline { 2 - 6 } & 1 день & 3 день & 7 день & 14 день & 21 день \\
\hline Опилки & $10,03 \pm 3,0$ & $21,92 \pm 3,0$ & $27,98 \pm 3,0$ & $29,13 \pm 3,0$ & $29,10 \pm 3,0$ \\
\hline Шерсть & $20,21 \pm 3,0$ & $48,10 \pm 3,0$ & $57,91 \pm 3,0$ & $59,67 \pm 3,0$ & $59,67 \pm 3,0$ \\
\hline Торф & $5,80 \pm 3,0$ & $9,34 \pm 3,0$ & $15,45 \pm 3,0$ & $16,06 \pm 3,0$ & $16,06 \pm 3,0$ \\
\hline Шерсть + опилки & $30,25 \pm 3,0$ & $39,01 \pm 3,0$ & $64,90 \pm 3,0$ & $65,40 \pm 3,0$ & $65,40 \pm 3,0$ \\
\hline Шерсть + торф & $21,67 \pm 3,0$ & $37,23 \pm 3,0$ & $39,82 \pm 3,0$ & $53,80 \pm 3,0$ & $53,80 \pm 3,0$ \\
\hline Опилки + торф & $15,20 \pm 3,0$ & $30,70 \pm 3,0$ & $44,10 \pm 3,0$ & $44,90 \pm 3,0$ & $44,90 \pm 3,0$ \\
\hline Шерсть + опилки + торф & $35,60 \pm 3,0$ & $55,90 \pm 3,0$ & $68,10 \pm 3,0$ & $70,30 \pm 3,0$ & $70,30 \pm 3,0$ \\
\hline
\end{tabular}


Количественной характеристикой процесса концентрирования является степень извлечения элемента. Степень извлечения дает достаточно полное представление о характере процесса и является критерием при определении оптимальных условий процесса.

Степень извлечения $S$ - величина показывающая, какая доля абсолютного количества элемента улавливается сорбентом:

$$
S, \%=\frac{\left(C_{\text {ucx. }}-[C]\right) \cdot 100}{C_{\text {uсx. }}} .
$$

Исследования показали, что природные сорбенты наиболее полно очищают почву от нефти за 14 дней. Степень извлечения для шерсти составляет 59,67\%, для опилок $29,13 \%$, а для торфа наименьшая - 16,06\%.

Сорбционная очистка нефтезагрязненных почв с применением многокомпонентных сорбентов позволяет сочетать волокнистую структуру шерсти, большую площадь поверхности опилок и пористую структуру торфа, что приводит к существенному увеличению сорбционной емкости. Степень извлечения нефти для многокомпонентного сорбента возрастает до 70,30\%.

\section{СПИСОК ЛИТЕРАТУРЫ}

1. Андерсон, Р. К. Охрана окружающей среды в нефтегазовой промышленности / Р. К. Андерсон, Р. Х. Хазинова // Обзор информации. Серия «Коррозия и защита в нефтегазовой промышленности». - М. : ВНИИ ОЭНГ, 1978. - 39 с.

2. Батюк, В. П. Применение полимеров и поверхностно активных веществ в почвах / В. П. Батюк. - М. : Наука, 1978. - 242 с.

3. Биоиндикация и мониторинг состояния нефтезагрязненных территорий Прикаспийской низменности: монография / Ц. Д. Даваева, Л. Х. Сангаджиева, З. Б. Бадмаева, А. А. Булуктаев. - Элиста : ЗАОр «НПП “Джангар”», 2014. - 152 c.

4. Булуктаев, А. А. Изменение эколого-биологические свойства светло-каштановых почв Калмыкии при загрязнении нефтепродуктами / А. А. Булуктаев, Л. Х. Саганджиева, Ц. Д. Дорджиева // Известия Саратовского университета. Новая серия. Серия: «Химия, биология, экология», 2013. - Т. 13, № 1. - C. 102-107.

5. Влияние нефти на почвенный покров и проблема создания нормативной базы по влиянию нефтезагрязнения на почвы / С. Я. Трофимов, Я. М. Ам- мосова, Д. С. Орлов [и др.] // Вестник МГУ. Серия 17. -2000 . - № 2. - С. 30-40.

6. Гамаюнов, С. Н. Гумусовый мелиорант «Нисаба» для повышения плодородия почв / С. Н. Гамаюнов, О. С. Мисников, А. Е. Тимофеев // Интеграция науки и образования - производству, экономике : сб. тр. межрегиональной науч.-техн. конф. - Тверь : ТвГТУ, 2012. - С. 148-154.

7. Грецкова, И. В. Очистка и восстановление почв после загрязнения их нефтью и нефтепродуктами : дис. ... канд. хим. наук / Грецкова Ирина Викторовна. - Самара, 2004. - $135 \mathrm{c}$.

8. Каменщиков, Ф. А. Нефтяные сорбенты / Ф. А. Каменщиков, Е. И. Богомольный. - Ижевск: НИЦ «Регулярная и хаотическая динамика», 2005. $268 \mathrm{c}$.

9. Мотузов, Г. В. Экологический мониторинг почв / Г. В. Мотузов, О. С. Безуглова. - М. : Академический проспект, 2007. -232 с.

10. ПНД Ф 16.1:2.21-98. Определение нефтепродуктов в почве. - М. : Федерал. центр анализа и оценки техногенного воздействия, $2012-44 \mathrm{c}$.

11. Телегин, Л. Г. Охрана окружающей среды при строительстве и эксплуатации газонефтепроводов / Л. Г. Телегин, Б. И. Ким, В. И. Зоненко. - М. : Наука, 1988. - 190 c.

12. Хазиев, Ф. Х. Изменение биологических процессов в почвах при нефтяном загрязнении и активация разложения нефти / Ф. Х. Хазиев, Ф. Ф. Фатхиев // Агрохимия, 1981. - № 10. - С. 102-111.

13. Халимов, Э. Н. Экологические и микробиологические аспекты повреждающего действия нефти на свойства почвы / Э. Н. Халимов, С. В. Левин, В. С. Гузеев // Вестник МГУ. Сер. 17. - 1996. - № 2.C. 59-64.

14. Adam, G. Effect of diesel fuel on growth of selected plant species / G. Adam, H. J. Duncan // Environmental Geochemistry and Health. - 1999. № 21. - P. 353-357.

15. Ammosova, J. M. Monitoring of soil degradation caused by oil contamination / J. M. Ammosova, M. J. Golev // Proceedings of the Conference «Towards Sustainable Land Use». - Vol. 2, 31. - Boon. - 1998. - P. 1231-1239.

16. Bish, D. L. Natural Zeolites: Occurrence, properties, applications / D. L. Bish, D. W. Ming (Eds.). - Mineral. Geochem, 2001. - V. 45. - P. 1-654.

17. McGrat, D. Oll sprillge on grassland effects on grass and soil / D. McGrat // Farm Food Res. 1988. - Vol. 19. - № 5. - P. 28-29.

18. McGill, W. B. Soil restoration following oil spills-A review / W. B. McGill // J. Can. Petrol. Technol, 1977. - Vol. 16. - № 2. - P. 56-64.

19. Radwant, D. B. Oil biodegradation around roots / D. B. Radwant, N. Sorkhoh, I. El-Nemr. Nature. - 1995. - Vol. 375. - № 27. - P. 302. 
20. Solntseva, N. P. Distribution of oil and soil products in soils of tundra landscapes within the European territory of Russian / N. P. Solntseva, O. A. Guseva // Proc. Intern. Symp. of physics, chemistry and ecology of seasonally frozen soils. - Alaska, 1997. - P. 449-455.

\section{REFERENCES}

1. Anderson R.K., Khazinova R.Kh. Okhrana okruzhayushchey sredy V neftegazovoy promyshlennosti [Environmental Protection in the Oil and Gas Industry]. Obzor informatsii. Seriya "Korroziya $i$ zashchita $v$ neftegazovoy promyshlennosti» [Overview of Information. Corrosion and Protection in the Oil and Gas Industry]. Moscow, VNII OENG Publ., 1978. 39 p.

2. Batyuk V.P. Primenenie polimerov $i$ poverkhnostno aktivnykh veshchestv $v$ pochvakh [The Use of Polymers and Surfactants in Soils]. Moscow, Nauka Publ., 1978. 242 p.

3. Davaeva Ts.D., Sangadzhieva L.Kh., Badmaeva Z.B., Buluktaev A.A. Bioindikatsiya $i$ monitoring sostoyaniya neftezagryaznennykh territoriy Prikaspiyskoy nizmennosti: monografiya [Bioindication and Monitoring of the Condition of OilContaminated Territories of the Caspian Lowland: Monograph]. Elista, Dzhangar Publ., 2014. 152 p.

4. BuluktaevA.A., Sagandzhieva L.H., Dordzhieva C.D. Izmenenie ekologo-biologicheskikh svoystv svetlokashtanovykh pochv Kalmykii pri zagryaznenii nefteproduktami [Changes in the Ecological and Biological Properties of Light Chestnut Soils in Kalmykia due to Contamination with Oil Products ]. Izvestiya Saratovskogo universiteta. Novaya seriya. Seriya: khimiya, biologiya, ekologiya, 2013, vol. 13, no. 1, pp. 102-107.

5. Trofimov S. Ya., Ammosova Ya.M., Orlov D.S., et al. Vliyanie nefti na pochvennyy pokrov i problema sozdaniya normativnoy bazy po vliyaniyu neftezagryazneniya na pochvy [Influence of Oil on the Soil Cover and the Problem of Creating a Regulatory Framework on the Impact of Oil Pollution on Soils]. Vestnik MGU. Seriya17, 2000, no. 2, pp. 30-40.

6. Gamayunov S.N., Misnikov O.S., Timofeev A.E. Gumusovyy meliorant «Nisaba» dlya povysheniya plodorodiya pochv [Humus Aameliorant Nisaba for Increasing Soil Fertility]. Integratsiya nauki i obrazovaniya - proizvodstvu, ekonomike: sb. tr. mezhregionalnoy nauch.-tekhn. konf. [Integration of Science and Education in the Spheres of Production and Economy: Collected Works of Interregional Scientific-Technical Conference]. Tver, TvSTU Publ., 2012, pp. 148-154.

7. Gretskova I.V. Ochistka $i$ vosstanovlenie pochv posle zagryazneniya ikh neftyu i nefteproduktami: dis. ... kand. khim. nauk [Cleaning and Restoration of Soils after Contamination with Oil and Oil Products. Cand. chem. sci. diss.]. Samara, 2004. 135 p.

8. Kamenshchikov F.A., Bogomolnyy E.I. Neftyanyye sorbenty [Oil Sorbents]. Izhevsk, NITs "Regulyarnaya i khaoticheskaya dinamika" Publ., 2005. $268 \mathrm{p}$.

9. Motuzov G.V., Bezuglova O.S. Ekologicheskiy monitoring pochv [Ecological Monitoring of Soils]. Moscow, Akademicheskiy prospekt Publ., 2007. 232 p.

10. PND F 16.1:2.21-98. Opredelenie nefteproduktov $v$ pochve [HDPE F 16.1: 2.21-98. Determination of Petroleum Products in Soil]. Moscow, Federal. tsentr analiza i otsenki tekhnogennogo vozdeystviya, 2012. 44 p.

11. Telegin L.G., Kim B.I., Zonenko V.I. Okhrana okruzhayushchey sredy pri stroitelstve i ekspluatatsii gazonefteprovodov [Environmental Protection in the Construction and Operation of Gas and Oil Pipelines]. Moscow, Nauka Publ., 1988. 190 p.

12. Khaziev F.H., Fatkhiev F.F. Izmeneniye biologicheskikh protsessov v pochvakh pri neftyanom zagryaznenii i aktivatsiya razlozheniya nefti [Change in Biological Processes in Soils under Oil Contamination and Activation of Oil Decomposition]. Agrokhimiya, 1981, no. 10, pp. 102-111.

13. Khalimov E.N., Levin S.V., Guzeev V.S. Ekologicheskie i mikrobiologicheskie aspekty povrezhdayushchego deystviya nefti na svoystva pochvy [Ecological and Microbiological Aspects of the Damaging Effect of Oil on Soil Properties]. Vestnik $M G U$. Seriya17, 1996, no. 2, pp. 59-64.

14. Adam G., Duncan H. Effect of diesel fuel on growth of selected plant species. Environmental Geochemistry and Health, 1999, no. 21, pp. 353-357.

15. Ammosova Ya.M., Golev M.Ya. Monitoring of soil degradation caused by oil contamination . Proceedings of the Conference "Towards Sustainable Land Use", 1998, vol. 2, pp. 1231-1239.

16. Bish D. L., Ming D. W., eds. Natural Zeolites: Occurrence, properties, applications. Mineral. Geochem., 2001, vol. 45, pp. 1-654.

17. McGrat D. Oll sprillge on grassland effects on grass and soil. Farm Food Res., 1988, vol. 19, no 5, pp. 28-29.

18. McGill W.B. Soil restoration following oil spills - A review. J. Can. Petrol. Technol., 1977, vol. 16, no. 2, pp. 56-64.

19. Radwant D.B., Sorkheh N., El-Nemr I. Oil biodegretion around roots. Nature, 1995, vol. 375, no 27, p. 302.

20. Solntseva N.P., Guseva O.A. Distribution of oil and soil products in soils of tundra landscapes within the European territory of Russian. Proc. Intern. Symp. of physics, chemistry and ecology of seasonally frozen soils. Alaska, 1997, pp. 449-455. 
Б.В. Цомбуева, З.В. Горяшкиева, Л.Ф. Щербакова. Метод очистки почвы от нефтяного загрязнения

\section{Information About the Authors}

Baira V. Tsombueva, Assistant, Department of Chemistry, Kalmyk State University named after B.B. Gorodovikov, Pushkina St., 11, 358000 Elista, Russian Federation, bairacom@mail.ru.

Zinaida V. Goryashkieva, Specialist of Collective Use Centre "Biovet", Kalmyk State University named after B.B. Gorodovikov, Pushkina St., 11, 358000 Elista, Russian Federation, goryashkievaz@mail.ru.

Lyubov F. Shcherbakova, Candidate of Sciences (Chemistry), Associate Professor, Department of Natural and Technical Safety, Yuri Gagarin State Technical University of Saratov, Politekhnicheskaya St., 77, 410054 Saratov, Russian Federation, shchlf@yandex.ru.

\section{Информация об авторах}

Баира Викторовна Цомбуева, ассистент кафедры химии, Калмыцкий государственный университет имени Б.Б. Городовикова, ул. Пушкина, 11, 358000 г. Элиста, Российская Федерация, bairacom@mail.ru.

Зинаида Валериевна Горяшкиева, специалист ЦКП «Биовет», Калмыцкий государственный университет имени Б.Б. Городовикова, ул. Пушкина, 11, 358000 г. Элиста, Российская Федерация, goryashkievaz@mail.ru.

Любовь Федоровна Щербакова, кандидат химических наук, доцент кафедры природной и техносферной безопасности, Саратовский государственный технический университет имени Ю.А. Гагарина, ул. Политехническая, 77, 410054 г. Саратов, Российская Федерация, shchlf@yandex.ru. 